América sin nombre, n. ${ }^{\circ} 22$ (2017) 13-15

DOI 10.14198/AMESN.2017.22.00

ISSN: 1577.3442 / eISSN: 1989-9831
Puede citar este artículo como:

Prado Alvarado, Agustín. "Presentación: Nuevos cuentos para el nuevo siglo XXI». El cuento hispanoamericano del siglo XXI. Agustín Prado Alvarado (coordinador). América sin Nombre, 22 (2017): 13-15, DOI: 10.14198/AMESN.2017.22.00

Link para este artículo: http://dx.doi.org/10.14198/AMESN.2017.221.00

\title{
Presentación Nuevos cuentos para el nuevo siglo XXI
}

\author{
Presentation \\ New stories for the new 21 st century
}

\author{
Agustín Prado Alvarado \\ Los buenos cuentistas son los magos más temerarios. \\ Samanta Schweblin
}

En estas dos primeras décadas del siglo xxi los escritores(as) de Hispanoamérica heredan una gran fortuna literaria del siglo xx: un canon de cuentos tallados por autores(as) que forman parte de los imaginarios literarios en América y España. El cuento como género narrativo adquirió en la América hispana una madurez y un estatuto de prestigio desde las primeras décadas del siglo anterior hasta alcanzar un reconocimiento internacional en otras literaturas. Para un escritor(a) o lector(a) de este nuevo milenio pensar en la tradición del cuento escrito en español es pasar (casi) obligatoriamente por la narrativa de Jorge Luis Borges o Julio Cortázar, a los que sumamos la obra cuentística de Juan Carlos Onetti, Silvina Ocampo, Luisa Valenzuela, Adolfo Bioy Casares, Juan Rulfo, Elena Garro, Juan José Arreola, Julio Ramón Ribeyro, Augusto Monterroso, Mario Benedetti y la lista podría continuar, sin embargo, fueron los cuentos de Borges y Cortázar los primeros que renovaron este género por los diversos formatos estilísticos, estructurales y temáticos que le imprimieron a cada uno de sus relatos.

En la historia del cuento en la cultura americana se puede establecer un recorrido sincrónico que suele ungir a la obra cuentística del uruguayo Horacio Quiroga (1878-1937) como el big bang del relato breve. En sus relatos más memorables encontramos una temática desde el legado fantástico hasta los temas centrados en los espacios rurales de la selva, casi todos marcados por el signo trágico en el destino de sus personajes. Quiroga es el primero en teorizar sobre la naturaleza del cuento en su famoso "Decálogo del perfecto cuentista» publicado en la revista Babel en 1927 al que debemos añadirle otros textos como "La retórica del cuento" editado en $E l$ Hogar de Buenos Aires en 1928. Esta poética del cuento lo emparenta con el cuento moderno, aquel que surge con el escritor norteamericano Edgar Allan Poe, el iniciador del cuento moderno en la literatura occidental, quien también fue el primero en desarrollar una reflexión teórica sobre la confección del relato breve. La estela de Poe, que hasta ahora no se apaga, fue un modelo para muchos escritores de fines del siglo XIX y especialmente del Modernismo, entre ellos Quiroga, quien lo consideraba su maestro.

Otro aspecto que ayudó a expandir la lectura de la obra narrativa de Quiroga fue la prensa; en diversos diarios de Uruguay y Argentina, se difundieron los cuentos, sin embargo, podemos mencionar que la poderosa obra narrativa de Quiroga tuvo un impacto en otros países de América muy posteriormente a los años en que se difundía en Montevideo o Buenos Aires y esto se explica porque en cada país el desarrollo del cuento tuvo sus propios derroteros aunque muchos de estos escritores todavía tengan un reconocimiento muy anclado en las fronteras nacionales como es el caso de cuentistas como Abraham 
Valdelomar (1888-1919) en el Perú o Pablo Palacios (1906-1947) en Ecuador.

A partir de los años 30 y en las siguientes décadas el cuento adquiere una presencia completa en la obra de los escritores quienes a pesar de alcanzar un prestigio con la publicación de sus novelas escribieron, publicaron y editaron en periódicos o revistas diferentes cuentos. Son los ańos en los cuales la narrativa hegemónica es el Regionalismo y el Indigenismo en el cual escritores como Miguel Ângel Asturias, Ciro Alegría o José María Arguedas publican sus cuentos, pero también es el momento del primer Borges quien edita su primer libro Historia universal de la infamia (1935), en este libro Borges se está empezando a apoderarse de diversas tradiciones literarias fuera del mapa latinoamericano.

Para los años cincuenta, la autoría de Borges quien ya publicó Ficciones (1944) y El Aleph (1949) está empezando a imprimir su huella en los escritores tan discretos como el peruano Luis Loayza o Julio Cortázar, quien ya ha editado Bestiario (1951) y Final del juego (1956) y Las armas secretas (1959). Ambos, Borges y Cortázar, adquirirán una resonancia con sus cuentos de temática fantástica que incluso la crítica literaria tuvo que acuñar la categoría de neofantástico (Alazraki, 1983) para analizar sus relatos. Ambos, además, desarrollaron sus posturas sobre el cuento, Borges lo consideraba el género narrativo ideal frente a la novela, por su parte Cortázar de alguna manera explicó sus ideas sobre el cuento en su famoso ensayo "El cuento y sus alrededores» (1969) y "Algunos aspectos del cuento» (1970) que se ha convertido en texto de consulta para los talleres de escritura y para explicar los códigos del cuento (no solamente del legado cortazariano). El camino estaba ya trazado y el cuento adquirió un prestigio que permanece en la cultura latinoamericana como un patrimonio literario.

En estas dos primeras décadas del siglo XxI ya podemos reconocer escritores(as) que han alcanzado un prestigio literario con la escritura continúa del cuento como parte de su vocación creativa. Otro rasgo que podemos detectar es su formación académica, principalmente en Facultades de Letras o Ciencias Sociales aunque no faltan los que provienen de los estudios de leyes y de las ciencias, además muchos de ellos ejercen como profesores universitarios en los programas de literatura o se encuentran insertados en los medios periodísticos y han reforzado el desarrollo de los talleres de creación literaria, una actividad que empezó a funcionar de manera sistemática desde los años 70 en Hispanoamérica y que forma un modus vivendi de muchos escritores en nuestros días.

La lectura de los cuentos y la comunicación con los autores también ha tenido un cambio radical por el impacto en nuestras vidas de los formatos electrónicos que permiten acceder gratuitamente a cuentos colgados en las redes de internet como Facebook o páginas especializadas o blogs personales y se pueden conocer las poéticas de los escritores al revisar las diversas entrevistas o lecturas colgadas en YouTube o en las páginas web creadas por los mismos autores donde archivan un valioso material crítico. Gracias a la revolución de internet el cuento del siglo xxi (y la literatura en general) alcanza un mayor y democrático número de lectores.

Podemos afirmar que en este siglo xxi existen autores que sin necesidad de publicar al principio en las grandes editoriales, aunque posteriormente y con todo derecho han accedido a casas editoras que cruzan fronteras, especialmente las españolas que apuestan por el cuento como Anagrama, Tropo Editores o Páginas de Espuma (una editorial dedicada exclusivamente al cuento) o la editorial mexicana Sexto Piso y en la Argentina la casa editora Eterna Cadencia. Sin embargo, desde otros territorios americanos podemos reconocer que hay un fortalecimiento de las denominadas editoriales independientes en cada país que ha permitido ediciones locales a precios más asequibles debido a los costos de importación de los libros.

Entre estos nuevos autores podemos mencionar a escritores peruanos como Carlos Yushimito, Jeremías Gamboa, Diego Trelles o a mexicanos como Antonio Ortuño o Yuri Herrera, quienes han alcanzado una mayor internacionalización, sin embargo, en estos años se ha producido un giro que está atendiendo la presencia femenina en la calidad de sus cuentos. A diferencia de lo ocurrido en el siglo $\mathrm{xx}$-donde las escritoras de cuentos en la se encontraban poco o casi nada atendidas por la crítica con mucha fortuna podían asomar tímidamente en las antologías, salvo las mencionadas Elena Garro, Silvina Ocampo, Luisa Valenzuela o Margo Glantz- los nombres de las mujeres en el presente siglo adquieren una relevancia completa como está ocurriendo con las argentinas Samanta Schweblin, Mariana Enriquez o Valeria Correa. Lo mismo podemos decir de la escritora boliviana Liliana Colanzi o las chilenas Alejandra Costamagna y Andrea Jeftanovic, o las peruanas Claudia Ulloa, Katya Adaui o Yeniva Fernández, las mexicanas Aurora Penélope Córdoba, Cecilia Eudave y Guadalupe Nettel (ambas empezaron a 
editar en los años 90, pero su escritura ha continuado y cobrado nuevos lectores en este nuevo siglo) o la escritora Vera Giaconi y la cubana Ena García, quienes son reconocidas por la crítica periodística, la crítica académica y el aprecio de la comunidad lectora en diferentes países de Iberoamérica, que esgrimen opiniones en favor de su alta calidad en la escritura del cuento.

Destacaremos solamente una muestra en el caso de Samanta Schwelbin, no solamente es una de las mejores cuentistas del orbe hispano, sino que muchos de sus cuentos, realmente magistrales, los podemos considerar como parte de los nuevos derroteros dentro de la tradición fantástica hispanoamericana, además en sus relatos percibimos esas relaciones familiares complejas y macabras. Los dos primeros libros de cuentos El núcleo del disturbio (2002) y Pájaros en la boca (2009) ubicados en los territorios de lo (neo)fantástico, sin embargo, en el tercer libro Siete casas vacías (2015) donde el formato fantástico cede a historias de la vida en los cuales la extrañeza y las atmósferas enrarecidas impregnan la vida cotidiana de sus personajes. En estas casi dos décadas la obra de Schweblin ha conseguido posicionarse a la cabeza del cuento en lengua española.

El presente número de América sin nombre aborda el cuento hispanoamericano del siglo xxi desde las diversas tradiciones del cuento escrito. Estos trabajos analizan desde múltiples metodologías los rasgos más visibles de los nuevos cuentos que han adquirido el fervor y favor de la crítica y de los lectores donde apreciamos los siguientes temas y estilos: las relaciones familiares, la compenetración con las ciudades, el tema (neo)fantástico, las problemáticas sociales, la migración, el impacto de la cultura de masas, la relación con la tradición anterior, el mundo sentimental y juvenil, las relaciones interculturales. Estas casi dos primeras décadas todavía son los periodos de reconocimiento que con los siguientes años y la distancia necesaria podremos corroborar la fortaleza de estos cuentos. Por ello este número monográfico es un primer acercamiento a los derroteros que están construyendo las novísimos escritores y escritores de la América hispana. 